\title{
VIVER E TRABALHAR EM TERRITÓRIO OCUPADO: a Palestina e seu povo ${ }^{1}$
}

\author{
Ana Maria Maciel Montenegro*
}

A Farouk Mardam-Bey

Desde 1967, os Territórios Palestinos - a Cisjordânia, ${ }^{2}$ a Faixa de Gaza e a parte leste da cidade de Jerusalém - estão submetidos à ocupação imposta por Israel: um período longo, que vem suscitando fenômenos novos e constrangedores, assim como formas de exclusão e de pobreza ${ }^{3}$ que significam uma ruptura em sua história. Essa região do Oriente Médio, que, desde a década de 1860, estava integrada no Império Otomano e no mercado mundial, destacava-se por um forte crescimento, demográfico e econômico, ligado à extensão das zonas agrícolas - como ao redor de Jaffa, onde a superfície dos laranjais quadruplicara entre 1850 e $1880^{4}$-, às exportações de algodão, cereais, azeite e sabão para a Ásia Menor e para a Europa.

* Doutora. Maitre de Conférence do Université de Paris XII - Créteil, França. ana-montenegro@club-internet.fr

${ }^{1}$ Tradução de Fernando Maciel Montenegro e revisão técnica de Rosa Freire d'Aguiar.

${ }^{2}$ A Judéia-Samaria, segundo os israelenses.

${ }^{3}$ Comparáveis àquelas que perduraram nos países ditos "em desenvolvimento".

${ }^{4}$ No cenário do Império Otomano, essa região pertencia a uma circunscrição político-administrativa mais extensa, "bilad al-Sham”, isto é, o "país" de Damasco (Laurens, p. 54-55, nota 3).
Assim, na Palestina voltada principalmente para o Mediterrâneo, próspera e com cerca de 470 mil habitantes (Sanbar, 1994, p. 14-15) ao final do século XIX, e 750 mil por volta de 1914, cidades e portos desenvolviam-se ao longo da costa: SaintJean d'Acre (próximo do "gouvernorat" francês do pequeno Libano ${ }^{5}$ ), Haiffa e Jaffa e, ao sul, numa zona menos urbanizada e mais pobre, próxima da fronteira egípcia, Gaza (Roy; Taubes, 1987) e seu porto. ${ }^{6}$ Toda essa região correspondia à Grande Síria até a divisão que se seguiu à Primeira Guerra Mundial.

${ }^{5}$ No contexto do desmembramento do Império Otomano, ao fim da Grande Guerra, os acordos de 1916 - assinados pelos ministros Sykes et Picot - delimitaram "zonas de influência“ francesa e inglesa que, em 1920, foram transformadas em "mandatos", englobando espaços que, hoje em dia e, respectivamente, correspondem ao Líbano, à Síria, ao norte da Mesopotâmia (Iraque) e ao sul da Anatólia (Turquia); a uma parte do sul da Mesopotâmia, assim como aos territórios que se enstendem a leste do Jordão (já no Iraque). No entanto, a Palestina - onde, desde 1917, a Declaração Balfour (ministro inglês) previra "um lar nacional para o povo judeu" - ficou à espera de um futuro estatuto internacional (Ver Laurens, (1991); Sanbar, (2002); Sellier, (1994; 1999).

${ }^{6}$ A Grande Síria, antes da divisão da região, após a saída da Primeira Guerra (ver nota 8). 
No interior, sobre as colinas da Cisjordânia e seus aqüíferos, ${ }^{7}$ Jerusalém destacava-se, "cidade santa” para as três religiões ditas do Livro - a Torá, a Bíblia e o Alcorão -, surgidas no Oriente Médio. Mais distantes e, portanto, mais próximas do Jordão - esse rio de renome bíblico, cujas águas escassas provêem da Palestina, do Líbano, da Síria, da Jordânia e se perdem no Mar Morto -, outras cidades alinhavam-se na rota comercial interior que conduz ao que era, então, a Grande Síria.

Ao final da Primeira Guerra Mundial, a Palestina - até então sob administração egípcia - viuse amputada de Gaza e transformada em uma "zona internacional” confiada à Inglaterra (1920) que, com esse "mandato", ${ }^{8}$ vai delimitar a Transjordânia e confiá-la aos Hussein (descendentes dos Xerifes da Meca), para os quais ela treinará um exército à sua própria imagem. Sobre uma parte desse território será instituído, em 1946, o reino Hachemita da Jordânia.

A Palestina não era, portanto, uma "terra sem povo" - fato que testemunhavam inúmeros visitantes - como Israel Zangwill, escritor inglês judeu que após uma estadia em 1897 afirmava em Manchester, em um discurso dirigido a um grupo sionista: "A Palestina em si já é habitada, o pashalik de Jerusalém Leste, com seus 52 habitantes $/ \mathrm{km} 2$, dos quais nem mesmo $25 \%$ de judeus, é duas vezes mais densamente povoada que os Estados Unidos”(Nur Masalha, 2002).

${ }^{7}$ Aqüíferos: reservas de água subterrânea, formadas pela penetração de chuvas. Na Palestina, esse recurso, de importância capital, provém do Mediterrâneo e se constitui em três lençóis freáticos principais, renováveis, na Cisjordânia e em Israel (que deles extrai aproximadamente $60 \%$ de seu consumo). Em Gaza, as colônias monopolizam a maior parte da água ainda disponível ou utilizável - inclusive porque a perfuração de poços muito profundos, concedidos aos colonos israelenses, facilita a penetração de água do mar. Paralelamente, a água deixada aos palestinos chega às torneiras cada vez mais carregada de lama, o que a torna salobra.

os $\quad{ }^{8}$ A queda do Império Otomano (1914) permitiu às grandes potências de então dividir o Crescente Fértil. Em 1916, foram assim delimitados dois "protetorados", um francês e outro inglês, e suas respectivas "áreas de influência” - cujos traçados serão modificados pela Conferência de Paris (1916), assim como as competências a eles atribuídas (de maneira a reduzir as interferências nas questões internas daquelas sociedades). Ocorre que a Sociedade das Nações estendia, em 1920, o "mandato" inglês à Palestina, que perdia, assim, o estatuto de "zona internacional" do qual pudera se beneficiar, embora uma carta do ministro de Relações Exteriores britânico já tranqüilizasse Lord Rothschild, afirmando: "o governo de Sua Majestade considera favoravelmente o estabelecimento na Palestina de um Lar nacional para o povo judeu". O mandato britânico só entrará em vigor em 29.09.1923 (Sanbar, 1994, p.14-31; Sellier, 1984, p.14).
Já em 1886, um chefe de colonos provenientes da Rússia temia "as implicações morais e os perigos do sionismo no campo político" (Nur Masalha, 2002, p. 27) e, em artigos publicados em hebreu no fim do século XIX, um intelectual russo liberal, inquieto com o etnocentrismo sionista, denunciava a exploração e a atitude dos colonos em relação aos camponeses palestinos: “... contra essa gente que lhes lembrava que há um outro povo na terra de Israel, que sempre aí viveu e que não tem a intenção de partir." ${ }^{9}$

Depois da Segunda Guerra Mundial, já no alvorecer da Guerra Fria, a Assembléia Geral da ONU, na sessão de 29.11.47, presidida por Oswaldo Aranha (um gaúcho), adotava por 33 votos a favor, 13 contra e 10 abstenções, o Plano de Divisão da Palestina: 55\% de seu território eram, assim, atribuídos a Israel - embora o Comitê Especial das Nações Unidas para a Palestina (UNSCOP ${ }^{10}$ ) pleiteasse a criação simultânea de um enclave internacional em Jerusalém, e de um Estado Árabe, que se estenderia sobre apenas $43 \%$ do território da Palestina histórica. A proposta, que tranqüilizava o rei da Transjordânia, foi, porém, rejeitada, embora a população árabe do território que seria destacado da Palestina para ser entregue ao novo Estado de Israel fosse duas vezes maior que o total de judeus ali presentes, isto é, cerca de 450 mil imigrantes aí chegados legalmente, ou não, durante o mandato inglês, e outros 150 mil descendentes de cerca de 56 mil judeus palestinos lá instalados desde 1920 (Abou Sitta, 2002, p.101). Essa minoria de judeus terá expulsado e transformado em refugiados 700 mil a 800 mil moradores de quinhentos e trinta e uma cidades e vilas - ou seja, $85 \%$ dos palestinos que viviam na área atribuída a Israel.

9 Ahad Ha'Am (Ascher Zvi Ginzeberg), The truth from the Land of Israel, complete works, Jérusalem, 1961, cit. em Mardam-Bey; Sanbar (2002, p. 27-28).

${ }^{10}$ Para obter o apoio do soberano hachemita, "protetor" da Meca e de Medina, as Cidades Santas dos muculmanos, os ingleses em luta contra o Império Otomano haviam prometido, vagamente, a constituição de um "grande" Reino nas zonas árabes conquistadas aos otomanos. Uma promessa ligada ao interesse inglês de afastar a França - "protetora das cristandades do Oriente Médio" - a fim de manter seu controle sobre o canal de Suez e sobre a rota das Índias (Dalloz, 1993, p.124). 
Quando foi proclamado o Estado de Israel (14.05.1948), os Estados Unidos foram o primeiro país a reconhecê-lo ${ }^{11}$ (mesmo porque a Europa, como "grande potência", já estava ultrapassada). Após a guerra de 1947-1949, que pretendia responder à recusa árabe dessa divisão, Israel definia-se como um Estado Judeu, adotava uma legislação segregacionista (Farsakh, 2003, p. 22) e já controlava $78 \%$ da Palestina do mandato - desde então submetida a um regime militar que não tardaria a expulsar mais da metade da população original. No final de fevereiro de 1948, um mês depois da anexação pela Transjordânia (atual Jordânia) de Jerusalém-Leste e da Cisjordânia, ${ }^{12}$ os palestinos se viram confrontados à Nakba, a "catástrofe" que resultou em 15.000 mortos e cerca de 780.000 a 800.000 expulsos, do total de 1.400 .000 habitantes das 531 vilas e cidades instaladas em $85 \%$ das terras destinadas ao novo Estado. ${ }^{13} \mathrm{O}$ armistício imposto aos exércitos vencidos do Egito, Líbano, Síria e Jordânia atribuía a Israel cinco milhões de acres adicionais; e o que restava da Palestina histórica era deixado, ou melhor, largado à tutela inglesa,

... suscitando uma dimensão trágica e uma consciência aguda de um destino anormal, que a ocupação de 1967 virá reforçar - assim como a evolução de um nacionalismo territorial. (MardamBey; Sanbar, 2002, p. 8)

Mediador local da ONU, o conde Folke Bernadotte testemunhou, indignado, a expulsão de cinco milhões de palestinos "depois da criação

\footnotetext{
${ }^{11}$ Para o historiador palestino Elie Sanbar, D.Ben Gourion que, no após-guerra, apostava na supremacia americana, já defendia, junto à comunidade judaica de Nova Iorque, a imigração ilimitada para a Palestina, sujeita ao controle da Agência Judia - o que o autor considera "premonitório da identificação-difusão no inconsciente americano, que assimila o nascimento de Israel ao dos EUA”. (Sanbar, 1994, p. 48-62).

${ }_{12}$ Note-se que, antes do voto do plano apresentado pela UNSCOP (1974), Abdallah, rei da Transjordânia, anunciara sua intenção de aprová-lo, com a condição de que sua competência sobre seu próprio reino fosse estendida à Palestina árabe (Laurens, p. 80; Sanbar, p. 62).

${ }_{13}$ Abou Sitta ,(2002, p.101-102); Jaber, (2002, p.114-116, 242); inclusive tabelas, datas, nomes de lugares e número de pessoas expulsas; Revue d'Etudes Palestiniennes, (2002, p. 32)
}

de Israel" que, por sua parte, recusou-se a admitir qualquer retorno, apesar da oposição feita por Yosef Sprinttzak, Secretário Geral da central sindical Histradout.

Tenho a impressão de que alguns fatos acontecem [...]. A questão não é saber se os árabes voltarão ou não. A questão é saber se os árabes são (ou foram) expulsos ou não [...] Quero saber quem comete os fatos (a expulsão)?. E os fatos são cometidos sob instruções [...] trata-se de "um plano de ação para expropriar e esvaziar pela força o país dos árabes (Morris, 2002, p.40).

Segundo Aaron Cohen, diretor do Departamento Árabe do partido israelense Mapam, em 1948:

... o que está ocorrendo corresponde a uma política concertada, e não a necessidades militares, como às vezes se pretende [...] Na verdade a transferência dos árabes para fora das fronteiras do Estado judeu está sendo operada [...] embora o esvaziamento das localidades árabes nem sempre seja necessário do ponto de vista militar [...] nem devido a uma insuficiência de forças para que se mantenha uma tropa nessas localidades (p. 40).

O desmembramento organizado de um território cuja população tornava-se, assim, majoritariamente refugiada, conduziu - dir-se-ia inexoravelmente - aos Territórios Ocupados. Assim, tratar hoje da questão do controle exercido por Israel sobre o trabalho dos palestinos e da Palestina ocupada significa analisar os meios administrativos e jurídicos, os preceitos filosóficos e mesmo religiosos, assim como os demais artifícios que fundamentam a desigualdade dos povos diante da lei - aplicada constantemente em detrimento do palestino, esteja ele onde estiver, face ao israelense, cuja cidadania atua eventualmente para garantir-lhe a impunidade. A menos que se trate de um árabe israelense, submetido por já mais de vinte anos a um "passe para circular", aos toques de recolher e à imposição quanto ao lugar de residência, sempre sob o risco de ver suas terras confiscadas (Farsakh, 2003, p. 22; Bishara, 2002, p. 43-48).

Assim, os $20.770 \mathrm{~km}^{2}$ atribuídos ao Estado de Israel ultrapassam em $70 \mathrm{~km}^{2}$ tanto a superfície decidida pela Assembléia da ONU em 1947, quanto aquela da qual o novo Estado se apoderou pela 
força das armas em 1967 - desde logo separando juridicamente da Cisjordânia o leste de Jerusalém e impondo a seus habitantes "atestados de residência”, sob pena de serem expulsos. Entre a série de outras normas abusivas e repressivas que correspondem à pretensão israelense de instalar, em Jerusalém, sua capital, há, por exemplo, a proibição feita aos futuros casais de aí se instalarem depois do casamento, se um dos cônjuges vivesse até então em outra zona da Palestina. Apesar dessa pretensão, a capital permanece em Tel-Aviv, onde até mesmo os Estados Unidos mantêm sua embaixada, assim como outros Estados, entre os quais o Brasil e a França (Mardam-Bey; Sanbar, 2002, p. 102).

\section{OS REFUGIADOS PALESTINOS, UMA POPU- LAÇÃO DIFÍCIL DE CONTABILIZAR}

Após o que foi, em 1948, a primeira guerra travada por Israel contra os Estados árabes, 112 mil palestinos expulsos de suas casas reagruparamse precariamente, às vezes em tendas, em áreas próximas, embora fora das fronteiras israelenses. As condições e a amplitude desse êxodo levaram à criação da UNRWA (United Nations Relief and Works Agency for the Palestiniens Refugees in the Near-East). Subordinada à ONU (como o são o Alto Comissariado para Refugiados ou a UNICEF), essa agência iniciou suas operações somente em $1950{ }^{14}$ Enquanto isso, os palestinos, "estupefatos com a conclusão dos acordos de armistício" e com as leis israelenses de 1948 e 1950, relativas às "propriedades abandonadas" e às "propriedades dos ausentes", tentavam ficar tão próximos quanto possível de sua pátria - até mesmo vivendo aos milhares ao relento, ou alojados em conventos (como no Líbano). Em 1950, dos 914 mil duzentos e vinte e hum refugiados registrados, 240 mil encontravam-se em Gaza, 764 mil na Cisjordânia, 160

${ }^{14}$ Os EUA, na qualidade de principal criador e doador da UNRWA (28\% do orçamento) nomeiam cinco dos onze diretores. A contribuição da Comunidade Européia e do Japão corresponde, respectivamente, a $28 \%$ e $8,8 \%$ do orçamento (Revue d'Etudes Palestiniennes, p. 83, 2003). mil e setecentos em Israel; e outros se resignaram a instalar-se em diferentes países árabes ou em outros lugares desse vasto mundo (Sanbar, 1994, p. 63).

Questionada sobre os fatos e práticas não conformes às suas resoluções, a Assembléia Geral da ONU, "tendo examinado a situação da Palestina em 11 de dezembro de 1948”, recordou o compromisso de todos os seus Estados-membros de agirem segundo a sua Carta e aplicarem os "princípios essenciais, como a retirada de tropas dos territórios ocupados, a inviolabilidade territorial e a independência política de cada Estado da região, pela criação de zonas desmilitarizadas", com vistas a assegurar "a transição para a regularização do estatuto da nação" palestina - ou antes, o que dela restava - e "permitir aos refugiados que o desejassem retornar aos seus lares o mais brevemente possível, viver em paz com seus vizinhos e ser indenizados..." (Nur Masalha, 2002, p. 40).

Esses princípios deveriam ser complementados pela elaboração "de propostas detalhadas tratando de um regime internacional permanente [...] e da desmilitarização de Jerusalém”. A Assembléia Geral preconizava também a criação de uma Comissão de conciliação que formularia recomendações relativas aos "Lugares Santos localizados naquela área e em outras regiões da Palestina”. Mas, duas décadas mais tarde, durante a Guerra dos Seis Dias (junho 1967), o exército israelense apoderar-se-á da parte leste da "cidade velha" de Jerusalém, onde, quase em seguida, destruirá boa parte das casas ao longo do Muro das Lamentações. Paralelamente à ocupação do Sinai egípcio e do Golã sírio pelas tropas israelenses, cerca de 250.000 palestinos serão expulsos da Cisjordânia e de Gaza (Staszewiski, 2002, p. 32). E outras levas se seguirão... Estima-se em 21 mil o número de partidas forçadas no período de 1968 a 1986.

Em 1954, a capacidade de acolhimento nos campos e colônias da UNRWA restringia-se a abrigar apenas 30\% dos refugiados; aos demais, ela fornecia apenas materiais de construção. Assim, 
... os mais ricos entre eles encontram um alojamento, enquanto os outros continuavam a viver em abrigos improvisados, grotas e casebres abandonados ao redor das principais cidades, gerando uma verdadeira crise urbana. ${ }^{15}$

Ainda que, pouco a pouco, as barracas tenham sido substituídas por construções sólidas, a maioria dos 607 mil cidadãos palestinos da Cisjordânia e dos 790 mil da "faixa” de Gaza ainda vivem nos “campos” (de refugiados), cercados e ameaçados pela multiplicação das colônias - inclusive algumas que o próprio Estado israelense considera ilegais -, e submetidos ao controle exercido sobre o território. Os outros refugiados permanecem ainda e majoritariamente em território árabe, tão perto quanto possível das fronteiras da Palestina: no Líbano, na Síria (onde o Golã e as margens do lago Tiberíades ainda estão ocupados) ${ }^{16}$ e na Jordânia (onde cerca de 60\% da população é de origem palestina). Para todos, persiste ainda e, sobretudo, o temor de que se instalar em casas de material sólido signifique adiar a volta ao lar territorial.

Mais recentemente, dos 3,8 milhões refugiados cadastrados ${ }^{17}$ na UNRWA, 96\% são palestinos, majoritariamente de cultura muçulmana (97\%) (Al Husseini, 2003, nota 1); os 4\% restantes representam cerca de vinte nacionalidades: são brasileiros, argentinos, franceses...etc. O Escritório Central de Estatística da Palestina também recenseou 4,5 milhões indivíduos em diáspora (1998) - “um "número global [...] que não se pode corroborar

${ }^{15}$ Sobre os refugiados, ver Al Husseini, 2003, p.71-85; Jaber, 2002, p. 241-245.

${ }^{16}$ Israel continua a ocupar as terras que se estendem entre o lago Tiberíades e o sopé do Djebel Druze. Essa montanha, de origem vulcânica, regada no inverno pelas chuvas provenientes do Mediterrâneo, é a fonte de um dos três afluentes que, precedidos pelo Hasbani libanês, formam o Jordão. Na sua margem esquerda, o Jordão recebe seu maior afluente, o Yarmouk, cujo alto curso corresponde a um segmento da fronteira entre a Síria (ao norte) e a Jordânia (ao sul). Tanto num caso como no outro, trata-se, assim, de zonas que Israel ocupou, a sudoeste da Síria e ao sul do Líbano (que vêm, atualmente, julho 2006, sendo bombardeadas e invadidas). Outros aportes de água vêm de sete rios de importância bem menor do planalto jordaniano.

${ }^{17}$ A UNRWA, criada para enfrentar essa situação, define como "refugiados" os residentes na Palestina entre 01.06.1946 e 15. 05.1948 que, quando da criação do Estado de Israel e do conflito decorrente, foram expulsos ou perderam seus lares e seus meios de subsistência, assim como seus descendentes. nem desmentir", considera Youssef Courbage. Segundo esse pesquisador reconhecido na matéria, somente dois segmentos de palestinos estariam bem identificados: os 3,1 milhões recenseados pela Autoridade Palestina e os 1,1 milhões palestinos cidadãos israelenses - com exceção daqueles que vivem na Jerusalém-Leste ocupada. Assim, na virada do século, somente $48,5 \%$ dos 8.797 .000 palestinos viviam no que lhes resta de seu antigo território.

Uma pesquisa realizada em 1998 chegara a um total de 4,2 milhões de palestinos, dos quais $83,2 \%$ são refugiados, sobre os 203 mil e quinhentos que viviam nos EUA. Nos países árabes, a proporção de refugiados fica em 83\% no Egito, 95\% na Síria e no Líbano e atinge a totalidade dos que vivem na Líbia, no Iraque, na Arábia Saudita e nos emirados do Golfo. Somente na Jordânia - ou seja, o mais perto possível da Palestina ocupada, e apesar de seu peso demográfico -, essa proporção é menor - embora $74,8 \%$ dos palestinos, inclusive boa parte daqueles aí nascidos, mantenham o estatuto de refugiados.

Em 2002, embora 5,2 milhões de palestinos continuassem ainda dispersos neste "vasto mundo" e numa verdadeira diáspora (contra 3 milhões em 1991 e 4,5 milhões em 2000) ${ }^{18}$ - há que lembrar que esses dados incluem também os árabes israelenses (descendentes dos palestinos de 1948). ${ }^{19}$ Mais de vinte anos se passaram desde que o Conselho Nacional Palestino e a OLP reconheceram o direito à existência de Israel - respectivamente em 1988 e em 1993 - dentro das fronteiras de antes de 1967, evidentemente. Mas a Palestina, mesmo reduzida a somente $22 \%$ de sua superfície histórica, ainda não obteve seu reconhecimento nem sua instituição como Estado.

${ }^{18}$ Courbage, (2002, p.182), segundo o Crescente Vermelho e o Escritório Central de Estatística da Palestina.

${ }^{19}$ Por muito tempo ameaçados pelo confisco de suas terras em 1976 e 1996 (quando o governo Netanyaou considerou aumentar a presença judia na Galiléia, onde os refugiados continuam mais numerosos); e ainda em 1999, quando os partidos árabes de Israel o reivindicavam, à época da eleição de Barak: (Grange; De Vericourt, 2000, p.55; Bishara, 2002, p. 72). Uma lei de 31de julho de 2003 nega a nacionalidade israelense aos Palestinos de Gaza e da Cisjordänia casados com israelenses (Revue Pour la Palestine, 2003, p. 29-31). 
Assim em uma região onde, às vésperas da criação de Israel, dois terços da população eram de árabes, estes já estavam reduzidos a 40\% quando estourou a guerra de 1967; e a apenas 38\% na segunda metade dos anos 1980 - o que decorre tanto da expulsão de 1948 (Sanbar, 1984) e das levas que se seguiram, quanto do crescimento demográfico nos países árabes do Machrek ${ }^{20}$ e em Israel, onde, em 55 anos, a população passou de 600 mil a aproximadamente cinco milhões. Essa população concentra-se (77\%) sobre apenas 15\% do território nacional, vive (21\%) em cerca de vinte cidades anteriormente palestinas e em outras tantas ditas "cidades de desenvolvimento" - onde é grande a parte de judeus orientais e de russos recentemente chegados de diferentes países da exEuropa do Leste, à procura de melhores condições de vida. Pode-se, assim, dizer que $85 \%$ do território israelense são "reservados" ao exército e a apenas $2 \%$ de sua população - ou seja, cerca de 160 mil habitantes dos moshavs e dos kibutz, que não produziriam mais que $2 \%$ do PIB nacional e onde muitas terras estão à venda. ${ }^{21}$

Concretamente, a população judia imigrada só teria valorizado, desigualmente, cerca de cinquenta e sete das quinhentas e trinta e uma cidades inseridas no espaço que lhe foi atribuído na divisão da Palestina. E, no total, somente trinta e quatro cidades foram inteiramente reconstruídas, o que significa que, uma vez suas populações originárias tendo sido forçadas a partir, quase $90 \%$ desses lugares continuaram vazios. Esse fenômeno reforça os que continuam a pedir a "aplicação, na prática, do direito ao retorno” e consideram que, contrariamente ao que ocorrera com os árabes palestinos em 1948, isso não significaria desapossar a população judia. Entre essas cidades, muitas estão hoje inseridas em zonas muito densas dos distritos costeiros de Haiffa (doze cidades) e de Jaffa (treze), ou ao longo das estradas de contorno de

${ }^{20}$ Machrek e Maghreb, isto é, Oriente e Poente do mundo "Un pays aboli de la carte" rabe.

${ }^{21}$ Bishara, (2002, p.74-75); Mardam-Bey; Sanbar, (2000, p.93, 109); Courtot, (2003, p.22) - 400.000, em 90-91; logo após à queda do Muro de Berlim, um milhão para uma população de 6,5 milhões, isto é, mais $20 \%$ na década de 1990.
Tel-Aviv, ou de cidades palestinas como Ramallah (nove), Tulkarém (oito), Gaza (seis) e Jerusalém (cinco); e outras se encontram em zonas de forte presença árabe. Assim a distribuição atual da população israelense seria bastante semelhante àquela de 1948 (Abou Sitta, 2002, p. 101-117), sem que, no entanto, cesse o controle sobre a Palestina - onde os habitantes de origem continuam a construir alojamentos que não lhes são destinados e estradas que desestruturam e retalham os Territórios Ocupados. Ou seja, impõem-se inúmeros desvios para que se chegue ao local de trabalho, o que é frequentemente impossível e tem conseqüências graves, tendo em vista os meios já tão escassos de que dispõe a maioria das famílias palestinas. Compreende-se, assim, que o árabe israelense Marwan Bishara - político e escritor reconhecido - fale e descreva um

... território relativamente vasto $\left(17.000 \mathrm{~km}^{2}\right)$
quase inteiramente roubado de 4,9 milhões de
refugiados. Se (os) da Faixa de Gaza fossem ins-
talados no sul do país do qual são originários, e os
refugiados do Líbano fossem autorizados a insta-
lar-se na Galiléia - região de onde foram expul-
sos - isso pouco mudaria a demografia da maio-
ria judia nas zonas onde ela reside - nem
tampouco a do país em seu conjunto. Ademais,
mesmo que a demografia evolua, qual seria o
problema? (2002, p.109).

Já em 1930-1948, tais questões interpelavam certos líderes sionistas que, diante dos massacres cometidos nas cidades onde a população palestina se recusava à partir (como Deir-el-Yassine, Dawaym e tantas outras) , teriam tentado encontrar eventuais "meios mais humanos para expulsar a população árabe”. ${ }^{22}$ Seja como for, esses fatos ocorreram "sem que nenhum soldado ou oficial, tendo cometido esses crimes de guerra, tenha sido investigado até o presente", afirmava mais recentemente Bennis Moris, um dos historiadores israelenses da "nova geração” - o que Alain Gresh ${ }^{23}$

22 Segundo os historiadores israelenses ditos da "nova geração”, os responsáveis pelo massacre de Deir-el-Yassine seriam os dissidentes do Irgun de Menahem Begin e do Stern de Ytizak Shamir (e não a Haganah de Ben Gurion); ver (Vidal, 2002, p.125-144).

3 Alain Gresh é filho de Henri Curiel, autor da obra L'Orchestre Rouge, assassinado em maio de 1978 no $5^{\mathrm{e}}$ arrondissement de Paris (ver Perrault, 1984, p.586). 
corrobora indiretamente, lembrando também que, antes mesmo da criação de Israel, Ben Gourion já colaborava com os "extremistas" de seu campo, para tentar neutralizá-los, e teria mesmo entregado alguns deles ao exército inglês. ${ }^{24}$

Na medida em que, ainda hoje, o governo israelense continua, abertamente, a reivindicar a soberania sobre Jerusalém, outros pesquisadores, como Ilan Halevy, interrogam-se sobre "o que nenhum oficial israelense fizera antes de Ehud Barak em Camp David”, às vésperas da primeira Guerra do Golfo (1991), ou seja, "propor um "acordo sobre tudo como condição a toda e qualquer negociação".

Se há qualquer reivindicação de soberania israelense com relação a Haram-al-Charif, trata-se de uma reivindicação sem precedentes: nem Golda Meir, nem Levi Eshol em 1967, nem mesmo Netanyahu jamais reclamaram a soberania política com relação a Haram-al-Charif, nem propuseram a construção de uma sinagoga sobre a esplanada! Havia uma espécie de acordo tácito estabelecido por Moshe Dayan sobre esse assunto desde 1967. Logo que E. Barak chegou e tirou da manga do colete essa reivindicação de soberania [...], o presidente Arafat afirmou a um de seus colaboradores: "isto é a prova de que ele não quer um acordo [...] e tenta minar a proposta global com essa condição totalmente inaceitável” (Halévi, 2002, p. 62).

\section{DA OCUPAÇÃO À COLONIZAÇÃO: construção da desigualdade e entraves ao trabalho}

Após quase trinta anos de ocupação, o palestino continua submetido à "permissão para deslocamento", a toques de recolher, a imposições, sob ameaça de ter suas terras confiscadas (Farsakh, 2003, p. 22).

A história jurídica da ocupação israelense da Cisjordânia é a de uma tentativa de conciliar dois objetivos fundamentalmente contraditórios: de um lado, proclamar que Israel governa segundo os princípios do direito e, de outro lado, colonizar uma região (Shehadeh, 1989, p.42).

${ }^{24}$ Ver "Israel Palestine sans préjugés", commentaire de l'ouvrage d'Alain Gresh, par S.Cypel, Le Monde, 8.03.2002.
Desde a ocupação da Faixa de Gaza e da Cisjordânia em 1967, o governo israelense cessava de fazer referência e declarava-se não-submetido à Quarta Convenção de Genebra (1949), ${ }^{25}$ relativa à proteção das populações civis em tempo de guerra - apesar do compromisso feito nesse sentido - e outorgava-se, assim, a prerrogativa de promulgar ordens militares que modificavam, de direito e de fato, o sistema jurídico em vigor na Palestina, sob o único pretexto de que este não seria palestino, mas jordaniano (Mansour, 1989, p. 43, 50). Daí a "fabricação" e promulgação de uma nova lei imobiliária, que compreendia definições, modalidades e condições de aquisição de terrenos públicos que negavam às jurisdições locais e históricas da Palestina qualquer poder em matéria de aquisição de bens imóveis. Paralelamente, por meio da "Lei sobre a Água" (1959) e de regulamentos militares $\left(\mathrm{n}^{\circ} 450-451\right.$ de 1971) - que caracterizavam como "propriedade pública submetida ao controle do Estado" os recursos hidráulicos dos Territórios Ocupados - o poder israelense se outorgava, para impedir os palestinos de dispor livremente desse bem raro na região, os meios jurídicos necessários para colocar em prática políticas discriminatórias no sentido de regular os volumes de água disponibilizados aos palestinos, daí em diante proibidos de procederem a novas perfurações de poços. ${ }^{26} \mathrm{O}$ conjunto do sistema revelava-se ainda mais "eficiente" à medida que essas leis militares, regulações e outros regulamentos relativos à sociedade civil eram apresentados apenas oralmente, embora esses textos, jamais publicados, possibilitassem e colocassem em prática uma nova realidade jurídica.

Conhecem-se casos isolados como no Chile, onde um ou dois decretos militares considerados documentos secretos não foram objeto de publicação. Entretanto, trata-se aqui do primeiro caso, levado à atenção do Comitê Internacional de Juristas, em que a legislação inteira de um território não é publicada em um órgão oficial acessível ao público (Shehadeh; Kuttab, 1981).

${ }^{25}$ Conferência de Genebra de 1949.

${ }^{26}$ O relatório ao qual B’Tselem se refere ao documento "Les eaux de la discorde", publicado em Revue Pour la Palestine (1999), e a um artigo de Jarry, E. (1981, p. 6). 
Recentemente, a professora e jurista francesa Monique Chemillier-Gendreau pronunciava-se sobre a questão, considerando que

O impasse no qual entraram as negociações israelo-palestinas não poderia ser explicado exclusivamente por um ou outro dos fatores de desacordo entre esses dois povos tais como são habitualmente enumerados, nem mesmo por sua soma. Na realidade, a situação atual desenvolveu-se historicamente numa dupla negação, aquela do direito nacional (no singular) do povo palestino a ser reconhecido como Estado, à maneira de todos os outros povos da Terra emergentes de um período de descolonização, e aquela do direito dos palestinos (no plural) que provêem da aplicação do direito internacional e, mais precisamente, do exercício do direito dos povos de disporem de si mesmos e também dos direitos do homem tais como proclamados internacionalmente (Chemillier-Gendrau, s.d., p. 285-287).

Para fundamentar juridicamente a desigualdade, e isso desde o começo dos anos 1980, a lei israelense definia e registrava como "residente nos territórios administrados” seus próprios cidadãos aí instalados, retirando-os, assim, da competência dos tribunais da Cisjordânia. Trata-se de um desvio jurídico que, "interposto por governo militar", resultava no não-reconhecimento da entidade nacional palestina e desqualificava o direito à autodeterminação da população por ela representada (Shehadeh, 1989, p. 49-50).

Assim, desde o começo, as leis e regulamentos aplicados aos colonos e às terras confiscadas em proveito deles na Palestina ocupada (desde 1967) - essa terra que os judeus mais pios queriam "redimir" - dependem de um direito, de um poder e de competências que os privilegiam em relação às leis que o ocupante reserva aos palestinos, esses não-cidadãos. Tal sistema induz, e, na verdade, institui diversas formas de discriminação e de arbitrariedade em matéria de subvenções, de ajudas ao desenvolvimento de atividades produtivas, de registro de empresas ou qualquer outra permissão ou documento comprobatório. Ipso facto, em matéria trabalhista, a questão do recurso à mão-de-obra palestina ficava submetida ao Estado judeu, representado nos Territórios Ocupados por um governador militar.

O domínio territorial da colonização reper- cute também sobre todos os locais, vilarejos, cidades e aglomerações palestinas e territórios, apoiado e reforçado pela criação de estradas que levam diretamente a Israel e cujo acesso é normalmente proibido aos palestinos. Toda a malha rodoviária tem sido, na realidade, modificada pelo ocupante. Assim, entre desvios, barreiras, controles, percursos impostos e caminhos proibidos, incluindo os da faixa de Gaza, as distâncias aumentam para os palestinos, a ponto de impedir, e mesmo proibir, toda circulação. Simultaneamente, a prática de "fechamento" dos territórios entrava na linguagem midiática, fossem eles externos - impedindo a circulação entre a Cisjordânia e Gaza e o acesso a Israel, ou a Jerusalém, embora só a parte oeste da cidade tenha sido atribuída a Israel pela ONU ou internos (cerca de 766 entre 1993 e 2000 (Grange; De Vericourt, 2000) proibindo então a circulação no próprio interior dos Territórios Ocupados. Tais "fechamentos", que a ONU não cessa de denunciar como punições coletivas, transformam os percursos cotidianos entre domicílio e trabalho ou escola e trabalho em dificuldades incontornáveis e repetidas, já que todas as conseqüências recaem sobre as populações afetadas. Também é assim quanto às perdas de salário devidas aos atrasos, a ausência forçada causada por proibições de circular, os fechamentos de estradas, de ruas e fronteiras sem pré-aviso, além da revista dos veículos e de seus passageiros. Tantas e tais medidas não podem ser consideradas como fatos isolados ou pontuais, visto que sua violência gera conseqüências para os trabalhadores e sua integridade física, uma vez acidentes e mortes se multiplicam nas barreiras. Segundo E. Djeredian, embaixador americano em Israel,

... um terço do PIB palestino depende, na realidade, da mão-de-obra palestina que trabalha em Israel. As exportações palestinas dependem amplamente do mercado israelense. A união aduaneira entre Israel e a Autoridade Palestina representa (para esta última) uma fonte importante de recursos. É por isso que a criação de fronteiras econômicas seria nociva, em particular aos palestinos (Djeredian, 2002, p. 87).

Por sua vez, o Banco Mundial notava que: 
... a retomada econômica iniciada em 1998 cessou brutalmente no começo da Intifada de 2002 e as estritas medidas de fechamento que foram tomadas a seguir. A porcentagem da população que vive abaixo do nível de pobreza (US\$ 2 por dia/per capita) é estimada atualmente entre $45 \%$ e $50 \%$. Apesar de perdas humanas, mortos e feridos, não poderem ser contabilizados no plano econômico, estimam-se em 305 milhões de dólares, ao fim de dezembro de 2001, as conseqüências materiais do conflito. ${ }^{27}$

A malha viária e a distribuição de colônias correspondem bastante bem às "zonas" estabelecidas pelos acordos de Oslo - que, embora superadas como parte de um acordo, nem por isso deixam de prefigurar a situação de nossos dias. Não faz muito tempo, Ariel Sharon dizia, a propósito de uma declaração da ONU que condenava o Muro: ${ }^{28}$ "ela é pior que os acordos de Oslo". É verdade que a declaração de Oslo II (1995) elogia o aumento de cotas de água alocadas à Autoridade Palestina, e considera necessária a cooperação na gestão do recurso nos Territórios Ocupados, objetivando a instituição de cotas correspondentes às respectivas necessidades e o respeito a elas.

Colocados em prática há pouco mais de uma década, os acordos de Oslo deveriam levar ao reconhecimento mútuo de Israel e da OLP (Oslo I, assinado em 13.09.1993) e a um acordo interino relativo à autonomia da Cisjordânia - cuja evacuação se faria por etapas, segundo as três zonas do acordo e o avanço das negociações, até a sua extensão a todo o território ocupado. Outro acordo de autonomia, relativo a Gaza e a Jericó, fora assinado no Cairo em maio de 1994, cuja aplicação deveria ter ocorrido, no mais tardar, em maio de 1995. O avanço da ocupação e do controle dos Territórios Palestinos pelo governo israelense e seus colonos interventores vai de encontro a esses acordos, diante do silêncio da "comunidade internacional" e apesar de uma resistência jamais desmentida. O período dito "interino" permitiu ao Estado judeu dobrar o número de colonos ins-

\footnotetext{
27 Rapport Banque Mondiale, (18.03.02), Documentation Française, (2002, p.53-56), Revue Pour la Palestine, (2003).

${ }^{28}$ Adotada em 22 de outubro de 2003, com cento e quarenta e quatro votos a favor e quatro contra (os de Israel, dos EUA, das Ilhas Marshall e da Micronésia).
}

talados na Cisjordânia e em Gaza (que corresponde a, pelo menos, 400 mil, aí incluídos aqueles que se instalaram em Jerusalém Leste), fazendo da Palestina um patchwork, uma colcha de retalhos cuja borda, se nada nem ninguém tentar impedi-lo, é o Muro - cuja construção se fez e se prolonga sem entraves-, o que contribui e mesmo provoca outras medidas repressivas que transformam todo e qualquer deslocamento em uma viagem longa e arriscada (a exemplo das 12 horas necessárias para percorrer os 100 km que separam Ramallah e Amã, com pernoite freqüente e quase inevitável nas cercanias da ponte de Allenby, que permite o acesso à margem esquerda do Jordão, já em território jordaniano ${ }^{29}$ ). Há outras tantas proibições que impedem os cultivadores de chegar a seus campos e de fazer sua colheita (estabelecendo-se, por exemplo, e sem aviso prévio, os dias permitidos e(ou) a faixa etária das pessoas que terão acesso aos campos, o que priva cruelmente os cultivadores da ajuda de seus filhos adolescentes aptos a esse trabalho).

Os abusos mais graves e mais simbólicos ocorrem, provavelmente, no acesso à terra e à água, apropriadas sem entraves pelas colônias que se constroem sem dificuldades - e de preferência sobre os aqüíferos (como os lençóis de Jenin, de Hebron e no vale do rio Jordão). A apropriação desses recursos leva também a uma transformação e mesmo a uma destruição da própria paisagem da Palestina, pois os palestinos vêem-se proibidos, em suas próprias terras, de perfurar poços. ${ }^{30}$

A distribuição de colônias israelenses deve também ser lida tendo como referência os acordos de Oslo, pois sua capacidade de controle sobre os Territórios Palestinos é maior ou menor segundo as "zonas" criadas por esses acordos. ${ }^{31} \mathrm{Na}$ "Zona C", sobre mais de $60 \%$ da Cisjordânia, Israel permitiu a instalação de cento e quarenta e quatro co-

${ }^{29}$ Ver Revue d'Études Palestiniennes (2003, p.50); Jaward; Paris, 2003. p.14-15).

${ }^{30}$ Ver Sanbar, E. "Revue Géo" 84.

${ }^{31}$ Ver Courtot, para quem, à época, pôde-se pensar que os EUA colocariam em prática estratégias relacionadas a uma globalização que integraria a região sob a hegemonia americana e marcaria "o fim da época na qual Israel desempenhava o papel de encarregado de negócios (deles)...". (Revue d'Etudes Palestiniennes, 2003, p. 22). 
lônias oficiais e vinte outras ditas "selvagens", com seus 171 mil colonos. Pelo menos vinte e cinco novas colônias foram instaladas desde a posse do primeiro governo Sharon, posteriormente reconduzido ao poder. Em fins de 2001, segundo o ministro israelense do Interior, em seis meses, o número de colonos havia aumentado em 4,8 mil. É verdade que o primeiro-ministro havia anunciado que nenhum desmantelamento de colônias ocorreria, como tampouco na Zona B (que corresponde a $27 \%$ da Cisjordânia). Ou seja, às margens dessa zona, Israel "permitiu" que cada um faça o que bem entender, seja qual for a distância, e de preferência o mais perto possível das grandes cidades palestinas. Ao norte, nas proximidades de Jenin - cidade-mártir, que sofreu uma destruição de amplitude inaudita, conduzida pelo exército israelense durante quinze dias e noites em abril de $2002^{32}$ - assim como em direção ao sul, numa zona que se estende entre a fronteira israelense a oeste, e a leste, nas cidades de Naplus e Ramallah, o número de colônias e o território por elas controlado se estende. Não só em torno, mas bem além de Jerusalém-Leste, alcançando Belém. Em direção leste, à partir de Jerusalém, e ao longo da estrada $\mathrm{n}^{\circ} 1$, margeada por bases militares, o território das colônias (como Maale e Adoumim) se expande antes de se reduzir um pouco, perto de Jericó. Prejudicada pelo traçado da zona A, onde a soberania palestina deveria ser plena, essa ultima cidade é gravemente ameaçada pela fragmentação dos territórios, inclusive porque a reocupação, ocorrida em 2002, prejudicou sua economia, cujos recursos, que dependem, em particular, de um cassino, são escassos e incertos.

Dali na direção ao Mar Morto (a sudoeste) e ainda na Zona C "deixada" ao controle palestino, as colônias multiplicam-se e se impõem numa área que se alarga e se prolonga em direção norte pela estrada paralela à fronteira com a Jordânia. Na direção oposta, para além das colinas da Palestina,

${ }^{32}$ Dados de um dossiê da ONG Human Rights Watch, e do artigo "Tive muitas satisfações em Jenin, muitas" (testemunho de um motorista de bulldozer israelense que trabalhou nessa operação), publicados na Revue d'Etudes Palestiniennes, 2002, p.38-67, 68-76. as colônias e o território por elas controlado se reduzem nas cercanias de cidades importantes como Qalkiliya e Tulkarem. ${ }^{33}$ Nessa região, onde um oleicultor chegou a perder suas 5 mil oliveiras, a cidade de Qaffin foi despojada de $80 \%$ de suas terras agrícolas, ${ }^{34}$ varridas pela construção do Muro, embora tenha obtido a ajuda e o apoio concreto de um grupo de oito municípios do “départament" francês Var-Alpes Maritimes, que financia uma cooperativa de projetos concretos voltados para os campos de oliveiras.

Nessas “zonas, A, B, C", situam-se também vários campos de refugiados que, a partir de Ramallah, se estendem em sentido norte, em direção e nas cercanias da cidade de Bir-Zeit e sua Universidade. E também em direção oeste, até o sul de Belém, havendo ai vários campos, como o de Desdeish, como mais ao norte, nas proximidades da aglomeração constituída por grandes cidades palestinas como Jenin, Nablus e Tulkarem (mencionadas acima), e em direção ao sul da Palestina Ocupada e também na proximidade da fronteira israelense e no sudoeste de Belém. Ainda mais longe, em direção de Hebron (El-Khalil), certas colônias multiplicam os ataques e outras formas de depredação contra essa venerável cidade da Palestina histórica.

Enfim, na Faixa de Gaza, ${ }^{35}$ mais de um milhão de Palestinos lutam para sobreviver tanto aos ataques quanto às arbitrariedades israelenses. Um terço deles vive em oito campos de refugiados, onde a água se torna cada vez mais escassa, à medida que aumenta o domínio dos 5 mil colonos sobre $40 \%$ desse território. Os bombardeamentos intensos e de alcance profundo, contra uma zona onde os lençóis freáticos estão muito próximos do Mediterrâneo, causam aqui, nas fronteiras do deserto do Sinai (Egito), o que equivale a uma "política de terra arrasada", pois a água do mar se infiltra nos lençóis já por demais explorados, tornando-os cada vez mais salobros e os contaminando, o que cons-

\footnotetext{
${ }^{33}$ Jornal Le Monde (12.01, p. 9-10), Atlas du Monde Diplomatique, (2003, 173p. e mapas).

34 "Palestine solidarité", jun. 2003, p.18-19.

${ }^{35}$ Sanbar, Revue Géo, op cit.
} 
titui uma grande ameaça tanto às plantações como à saúde da população, ainda mais quando a falta de recursos torna quase impossível a limpeza das ruas e o serviço dos lixeiros. Nesse contexto, a colônia de Netzarin se "distingue"por provocações sempre renovadas, sabendo-se que a rede policial é da ordem de um sobre cinquenta habitantes e que o governo israelense persiste em destruir sistematicamente o que resta das atividades industriais e de serviços que, além de proibidos, são bombardeados por aviões ou mísseis (como ocorreu, por exemplo, com as oficinas de fabricação ou reparação que utilizam metais). Sob pretexto de segurança, ou de "represália" de tudo e de nada, bombas largadas por Israel (25 e 26.10.2003) destruíram três edifícios residenciais, cujos quatorze andares "ameaçavam" as colônias. Isso ocorreu pouco depois de um comunicado oficial israelense sobre uma "operação" que resultara em, ao menos, duzentas mortes e deixara mais de 2 mil pessoas sem abrigo" (segundo a Radio France Internationale, 4.11.03).

Face à arbitrariedade do poder militar dos governos israelenses, os palestinos - majoritariamente desempregados e confrontados com a falta de água, de matérias-primas, de ferramentas, de produtos e de outras instalações que as tropas obstinam-se em destruir regularmente, sem alívio nem motivo - são, por assim dizer, proibidos de todo o comércio com o exterior, mesmo quando se trata "apenas" dos recorrentes "fechamentos" dessa zona. Assim, os homens, mulheres e crianças dos Territórios Ocupados "oscilam entre desespero e ódio, com a convicção de estarem sendo reduzidos à categoria de objetos, com o sentimento de terem sido traídos". O que não os impede de continuarem a resistir e a se opor, tanto quanto possível, ao empreendimento israelense de colonização - como testemunhou uma jornalista:

Doravante, a Cisjordânia e Gaza são duas imensas prisões, cujo céu não é nem mesmo aberto. Submetidos ao regime de toque de recolher que os retém em suas casas de maneira quase permanente desde o último mês de agosto e que os asfixia lentamente, os palestinos dos territórios ocupados se vêem reduzidos à categoria de obje- tos e oscilam entre desespero e o ódio e o sentimento de terem sido traídos [...] Com a guerra, os chefes de família perderam - como quase todos seus compatriotas - o pouco que lhes restava: o direito de entrar em Jerusalém Oriental; o direito de exportar seus agrumes, isto é, seu trabalho, para a Jordânia; os meios de pagar seus impostos e de obter o famoso cartão cor de rosa, "certificado de bom comportamento", renovável a cada dois anos, sem o qual tudo se torna proibido: viajar, conduzir [transportes] e até mesmo passar de uma localidade a outra, já que o exército não só restabeleceu as fronteiras da Cisjordânia, mas instituiu espécies de 'bantustões", num total de cinco, no interior do território... O chefe de família perdeu seu emprego e como, pela primeira vez neste ano, não pôde pagar o montante cada vez mais insuportável de impostos, teme o fechamento da pequena empresa madeireira por ele dirigida. Seus quatro filhos estão também desempregados - incluído aquele que, nos últimos anos, havia encontrado um emprego de eletricista em Israel [...], mas que o perdeu com a guerra. Mal saídos dos toques de recolher intermináveis, os palestinos viram os impostos de 1991 reclamados manu militari abaterem-se sobre eles uma verdadeira epidemia de multas de todos os gêneros que irão alimentar os cofres israelenses... (Bauge, 1991).

Esse trecho, de um artigo longo e bem informado, retrata bem o quotidiano e os problemas de uma ocupação cuja permanência a torna cada vez mais dura e ousada. Assim, o conteúdo e as condições divergem cada vez mais entre, de um lado, a denominação Territórios Ocupados e, de outro, a concretização do empreendimento demográfico, social, territorial e econômico de uma política de colonização que nunca deixou de dizer seu nome e seus objetivos.

Nesse contexto, o desmantelamento de algumas “colônias ilegais" pequenas e dispersas não é mais que um jogo de cena, uma representação "para inglês ver", de uma política de "fatos consumados", cujo objetivo central é apoderar-se e submeter a economia e a população dos Territórios Palestinos a Israel; uma política que visa e consegue impor formas de dependência que não se restringem, nem se poderiam restringir, a seus aspectos puramente econômicos.

Efetivamente, antes da Guerra do Golfo, um decreto militar israelense-aplicado já então há vinte anos na Cisjordânia e a um decênio em Gaza - concedia uma "permissão geral" de entrada em Israel a todo habitante dos Territórios Ocupados, o que, segundo Samira Hass (correspondente nos Territó- 
rios Ocupados do jornal israelense "Haaretz"), facilitou a circulação e as relações entre os palestinos dos Territórios Ocupados e os árabes de Israel.

Os "gazauitas" foram os primeiros aos quais Israel impôs um cartão magnético, que também possuía a função de segunda carteira de identidade, com o detalhe de que sua renovação era paga e anual. Essa carteira era talvez menos restritiva que a "carteira verde", que simplesmente nega aos palestinos o direito de entrar em Israel. Imposta inicialmente àqueles que o ocupante via como "ameaça” à sua própria segurança, a nova carteira abrange uma maioria de palestinos da Cisjordânia que, antes de 1991, podiam “ir e vir”. A nova norma entrou em vigor antes mesmo que certos trabalhadores (comerciantes, doentes, colaboradores importantes ou outros palestinos "bem" vistos junto às autoridades da ocupação) tivessem a ela direito. Em Jerusalém, também, certos regulamentos foram pouco a pouco impostos às diversas "categorias" da população e, pouco a pouco, a toda a Palestina. O novo sistema logo se revelou pernicioso, inclusive em relação aos serviços sob responsabilidade da Autoridade Palestina, em particular quando novas regras vêm regularmente adicionar-se à outras tantas restrições, como as que impõem a todos os habitantes da Palestina uma hora-limite para admissão quotidiana nos Territórios Ocupados. ${ }^{36}$

${ }^{36}$ Como outras, essas proibições aumentavam em concomitância (ou quase) com os acordos de Madri e de Oslo... nificava impedir, com mais freqüência e duração que antes, toda e qualquer saída dessa "Faixa" de $600 \mathrm{~km}^{2}$. Seu 1,1 milhão de habitantes tampouco podia sair de casa, a não ser para mudar-se para a Cisjordânia, o que já acontecera três ou quatro anos antes em Hebron (El-Khalil), por imposição de 500 judeus ultra-ortodoxos, protegidos por mil e quinhentos soldados israelenses. A evacuação parcial dessa cidade (em 1996), seguida da transferência parcial de seu controle à Autoridade Palestina, deu-se num contexto que deve ser mencionado, ou seja, pouco antes do verão de 1997, quando o consumo médio de água era de 2881./pessoa em Israel e de 58l./palestino. Nessas condições, para os palestinos, a única saída era adquirir água junto aos proprietários, que revendiam a preços exorbitantes a água comprada em outros poços, públicos ou privados.

\begin{abstract}
O grau do absurdo foi alcançado a partir de outubro de 2000: estudantes perderam o direito de ir à Universidade, doentes e mulheres grávidas eram retidos nas barreiras das estradas, os técnicos municipais deviam munir-se de uma autorização israelense para consertar uma canalização, os escritórios administrativos funcionavam com a metade de seus efetivos, os caminhõescisterna transportando água perderam o direito de entrar nas cidades, o preço dos trajetos triplicou com a obrigação de se trocar de transporte coletivo a cada $20 \mathrm{~km}$ e as pessoas passavam horas e horas enfileiradas retidas nas barreiras nas estradas. Ou seja, as mercadorias levavam menos tempo para fazer o trajeto entre o porto de Ashod e a China do que entre Ashod e Nablus (Hass, 2002, p. 3-19).
\end{abstract}

Diferentes formas de controle foram e são também impostas em estradas, onde blocos de cimento e outros obstáculos tornam os percursos cada vez mais tortuosos e arriscados - sobretudo nas proximidades das colônias israelenses, que não cessam de expandir-se. Essa é uma realidade que o Muro não buscou ocultar, pelo menos desde fins de outubro 2003, quando Ariel Sharon anunciou a construção de outra "linha" de proteção ao longo do rio Jordão. Esse Muro, de oito metros de espessura, cuja construção se fez nos Territórios Palestinos sem entraves da "comunidade internacional", tornou mais eficaz o bloqueio de inúmeras passagens, provocando esperas intermináveis, separan- 
do as famílias, destruindo campos e plantações, inclusive proibindo seu acesso aos agricultores palestinos, em particular na época das colheitas. Isso agravou as formas cotidianas de submissão dos palestinos aos oficiais e soldados israelenses.

Vinte quatro anos após sua ocupação, a Cisjordânia, Gaza e o Golan permanecem sob dominação estrangeira. Israel continua a instalar suas colônias e a violar as convenções de Genebra sobre a proteção das populações, mas o governo (Sharon) não é julgado em Washington segundo as mesmas normas aplicadas aos outros paises (Halimi, 1991).

Na época em que foi escrito o trecho acima, um senador democrata americano confirmava o que já deixara de ser um indício - ou seja, que "as concessões israelenses não serão jamais um requisito à ajuda americana”. O que faz lembrar que o Estado de Israel, já em 1991, era um dos maiores beneficiários da ajuda americana, assim como Egito e a Turquia, seguidos pelo Paquistão e as Filipinas.

No mesmo número do jornal Le Monde Diplomatique, o jornalista libanês Samir Kassir ${ }^{37}$ explicava a dificuldade para a Palestina de ter reconhecida a sua especificidade - a qual ela não cessou de afirmar desde meados dos anos sessenta. Essa dificuldade contribuiu, já naquela época, para que Yasser Arafat (Abou Ammar) e seus dois companheiros Abou Iyad e Abou Jihad ${ }^{38}$ demonstrassem que a liberação dos Territórios Palestinos é um requisito para a unidade árabe.

\section{CONCLUSÃO}

Até hoje, Israel não conseguiu, nem social nem politicamente, controlar totalmente os Territórios Palestinos. A ocupação os empobrece progressivamente, inclusive devido à ação da "comunidade internacional" - que atua como interveniente político na mediação de inúmeros acordos, até mesmo os científicos, nas licenças de fabricação

\footnotetext{
${ }^{37}$ Samir Kassir foi assassinado a tiros em Beyrouth, dentro de seu automóvel, em 2006.

${ }^{38}$ Ambos assassinados, um pelos israelenses, o outro por
} grupos palestinos dissidentes. de armamentos e outras tecnologias avançadas. Tais fatos aumentam as possibilidades, para o governo israelense, de recorrer a meios alternativos para tentar reduzir a oferta de trabalho aos palestinos, através de abandonos forçados, para excluí-los desse mercado. Mas há também de levar em conta que, paralelamente, Israel se beneficia do alto nível de formação dos palestinos, graças à escolarização promovida pela UNRWA nos campos de refugiados. Assim, por uma dessas ironias da história, a mão-de-obra dos Territórios Ocupados é a mais bem-formada do Oriente Médio, até porque tais políticas são implementadas há mais de trinta anos.

A Palestina e seu povo sobrevivem desde 1967, apesar de tudo o que tem dilacerado seu tecido social, econômico e institucional, em Gaza como na Cisjordânia, territórios de um espaço nacional cravejado pelas colônias e pela ação socioeconômica e jurídico-militar do Estado de Israel. Esse Estado, membro da ONU, ao qual, nas vésperas do terceiro aniversário da Intifada "AlAqsa" - cujo início coincidiu com a visita de Ariel Sharon à Esplanada das Mesquitas em 29 de setembro $2000^{39}$ - o padrinho norte-americano concedia uma espécie de "permissão de demarcação / colonização". Isto é, uma medida que, por meio de um avanço de $20 \mathrm{~km}$ sobre a Cisjordânia, iria autorizá-lo à estabelecer uma continuidade entre seu próprio território e a colônia de Ariel, com a única condição de fazê-lo com material modular...!

Essa "permissão de construção", fora do comum, mantém aberta as portas para novas usurpações territoriais, além de instituir "o" Muro - um dos feitos de uma ilegalidade que perdura e "normaliza" o cerco concreto e simbólico do que ainda sobra da Palestina e de seu povo... Um dado político que nos remete à reflexão de DI MEO sobre a "dupla dimensão do território, isto é, sua

${ }^{39}$ O relatório Mitchell concluiu que nenhuma prova exis-
te que permita dizer que a série de confrontações entre
palestinos, majoritariamente desarmados, e o exército
israelense hiper-armado e que não conhece entraves no
uso da força, teria sido iniciada com o conhecimento de
causa da Autoridade Palestina - a propósito(ver Bishara,
2002, p.120).

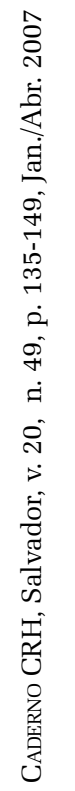


natureza material, geográfica no sentido próprio do termo, e seu conteúdo ideológico ou ideal”:

...se a autonomia funcional dos territórios hoje não existe mais, as amarras espaciais da territorialidade ainda persistem, mais sólidas que nunca... as modalidades de nossas relações com o espaço são o fruto sempre fecundo de uma imutável dialética social do material e do ideal coletivos. (Di Meo, 1998, p.90-91)

O fechamento, que impõe forte preconceito tanto à economia quanto ao indivíduo, é efetivamente uma arma política - no sentido de favorecer a corrupção, o individualismo, a esperteza , o "jeitinho", a figura do "vip", prejudicando a maioria. Isto é, o fechamento favorece o individualismo "venha ele de onde vier". A jornalista israelense Amira Rass considera que o "campo da paz" não teria se dado conta que o fechamento recorrente difere de muito da antiga "Linha Verde" e, nesse sentido, lembra:

Após Oslo, o fechamento era sinônimo de asfixia - que a resistência e a revolta, transformaram em sinônimo de medo físico e da necessidade de superar esse medo. (Hass, 2002, p.10)

(Recebido para publicação em julho 2004) (Aceito em agosto de 2006)

\section{REFERÊNCIAS}

ABOU SITTA, Salmam. Un pays aboli de la carte. In MARDAM-BEY, Farouk; SANBAR, Elias. Le droit au retour: le probleme des refugiés paliestiniens. Paris: Actes de Sud, 2002. p.101-117.

AHAD HA'AM (Ascher Zvi Ginzeberg) The truth from the land of Israel, complete works, Jérusalem, In: MARDAM-BEY, Farouk; SANBAR, Elias. Le droit au retour: le probleme des refugiés paliestiniens. Paris: Actes de Sud, 1961. p. 27-28.

¿ AL HUSSEINI, Jalal. L’UNRWA et les réfugiés. Revue $\therefore$ d'Etudes Palestiniennes, Washington, D.C. Institut des Études Palestiniennes. n. 86 p. 71-85, 2003.

ATLAS DU MONDE DIPLOMATIQUE. La Cisjordanie à la veille de la seconde intifada. Paris: jan., 2003. 173p. + mapas.

BANQUE MONDIALE. Rapport . Paris: 18. 03. 2002. 53p.

BAUGE, Florence. Le Monde Diplomatique, Paris, maio 1991.

BISHARA, Marwan. Palestine - Israel: la paix ou l'apartheid. Paris: La Découverte et Syros (édition augmentée et mise à jour); La Découverte (sur le vif), 2002. 153p.

BOTIVEAU, Bernard. Des institutions en construction. In: GRESH, Alain; BILLION. Didier. [S.l.,s.n.,s.d.], p. 3745 .

CHEMILLIER-GENDRAU, M. Le retour des Palestiniens en exet e le droit international. [S.l.,s.n.,s.d], p. 285-287.

COURBAGE, Youssef. La demografie des Palestiniens... In : MARDAM-BEY, Farouk; SANBAR, Elias. Le droit au retour: le probleme des refugiés paliestiniens. Paris: Actes de Sud, 2002. p.182.

COURTOT, T. Revue d'Etudes Palestiniennes. Washington, D.C. Institut des Études Palestiniennes, n. 87, p. 22 , 2003.

DALLOZ, Jacques. La création de l'état de l'Israel vu par la presse française. Les médias et l’événement. La Documentation Française, Paris, p. 124, 1993.

DI MEO, G. Geographie sociale des territoire. Paris: Nathan Université, 1998. p. 90-91.

DJEREDJIAN, Edward. Embaixador americano, diretor do James Baker III Institut for Public Policy, Rice University. Problèmes politiques et sociaux, abril 2001. Documentation Française. Paris, p.87, 2002.

LES EAUX de la discorde. Revue pour la Palestine, Paris, fev./mars, 1999 (Nouvelle série n.17).

FARSAKH, Leila. De l'Afrique du Sud à la Palestine. Le Monde Diplomatique. Paris, p. 22. nov., 2003.

GRANGE, Jocelyn; DE VERICOURT,Guillemette. Questions sur les Palestiniens, les essentiels. Milan: 2000. 64p.

GRESH,Alain; BILLION, Didier (Dir.). Actualité de l'Etat palestinien. Bruxelles: Editions Complexe, 2000. 191p.

HALEVI, Ilan. Face à la guerre. Lettre de Ramalla. Sindbad:Actes Sud, s.d., p. 73.

Revue d'Études Palestiniennes. Washington, D.C.

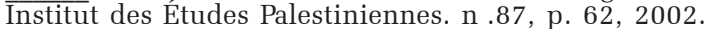

HALIMI, Serge. Le Monde Diplomatique, Paris, maio, 1991.

HASS, Amira. La Palestine sous la botte. Revue d'Etudes Palestiniennes. Washington, D.C. Institut des Études Palestiniennes, n.83, p.3-19, 2002.

JABER, Hana. Economie et sociétés: qu'est-ce qu'un camp de réfugiés? In: MARDAM-BEY, Farouk; SANBAR, Elias. Le droit au retour: le problème des refugiés palestiniens. Paris: Actes de Sud. 2002. p.233-261.

JARRY, E. Le Monde Diplomatique, Paris, set., p. 6, 1981. JAWARD, S.A.; PARIS, G. La paix en péril au ProcheOrient: ces dix ans qui changent tout. Le Monde, Paris, p.14-15, set., 2003.

LAURENS, Henry. Paix et guerre au Moyen-Orient. L’Orient arabe et le monde de 1945 à nos jours. Paris: Armand Colin/HER, 1999. 560p.

Le grand jeu. Orient arabe et rivalités internationales. Paris: Armand Colin/HER, 1991. 447p.

MANSOUR, Antoine. Les conditions économiques dans les territoires occupés. In: MANSOUR,Camille. (Dir.) Les Palestiniens de l'intérieur. Les livres de la Revue d'Etudes Palestiniennes. Washington, D.C., Institut des Études Palestiniennes, 1989. p. 77-97

MANSOUR, Camille (Dir.) Les Palestiniens de l'intérieur. Les livres de la Revue d'Etudes Palestiniennes. Washington,D.C., Institut des Études Palestiniennes, 1989. 291p.

MARDAM-BEY, Farouk; SANBAR, Elias.Le droit au 
retour: le problème des réfugiés Palestiniens. Paris: Actes Sud, 2002. 401p.

MORRIS, Benny. 1948 and after. In: MARDAM-BEY, Farouk; SANBAR, Elias.Le droit au retour: le problème des réfugiés Palestiniens. Paris: Actes Sud, 2002. p.40.

NUR MASALHA. Le concept de "transfert" dans la doctrine et dans la pratique du mouvement sioniste. In: MARDAM-BEY, Farouk; SANBAR Elias. Le droit au retour: le problème des réfugiés Palestiniens. Paris:Actes Sud, 2002. p. 5-59.

PERRAULT, Gilles. Un homme à part. Paris: Barrault, 1984. 586p.

RÉVUE D’ÉTUDES PALESTINIENNES. MARDAM-BEY, Farouk (Dir.), Washington, D.C. Institut des Études

Washington, D.C. Institut des Études Palestiniennes, n. 83, p. 32, 2002.

n. 85, p. 38-67, 68-76, 2002.

n.86, p. 83, 2003.

n. 87, p. 50, 2003. Palestiniennes. Disponível em: www.palestine-studies.org

ROY,Sara; TAUBES,Gary. Gaza hors des regards. Revue d'Etudes Palestiniennes, Washington, D.C. Institut des Etudes Palestiniennes, n.25, p.73-96, 1987.

SANBAR, Elias. Palestine 1948, l'expulsion. Livre de Revue d'Études Palestiniennes, Washington, D.C., Institut des Études Palestiniennes,1984. 235p.

Les Palestiniens dans le siècle. Paris: Gallimard, 1994. 176p. (Découvertes Gallimard, 201)

SHEHADEH, Raja. La politique juridique d'Israel dans les Territoires Occupés. In: MANSOUR, Camille (Dir) Les Palestiniens de l'intérieur. Les livres de la Revue d'Etudes Palestiniennes. Washington, D.C., Institut des Études Palestiniennes, p. 41-51.1989.

- KUTTAB, J. Cisjordanie la primauté du droit. Paris: Le Sycomore, 1981

STASZEWISKI, Michel. L'État juif, de le utopie au cauchemar. Revue d'Études Palestiennes. Washington, D.C., Institut des Études Palestiniennes. n. 83, p. 32, 2002

VITAL. Dominique. D’une intifada à l'autre, Israel face à son histoire MARDAM-BEY, Farouk. SANBAR, Elias. Le droit au retour: le problème des réfugiés Palestiniens. REVUE POUR LA PALESTINE. Paris, n. 39, p. 29-31, Paris: Actes Sud, 2002. 401p.

\section{VIVER E TRABALHAR EM TERRITÓRIO} OCUPADO: a Palestina e seu povo

\section{Ana Maria Maciel Montenegro}

Este artigo analisa de uma perspectiva histórica os diferentes meios jurídicos e administrativos bem como as resoluções de órgãos internacionais na regulação de uma área de disputa entre judeus e palestinos - a faixa de Gaza. A partir de consulta à imprensa e em revistas acadêmicas especializadas a autora revela as dificuldades vividas pelos palestinos na organização da vida e do trabalho, pelos bloqueios de circulação, que os transformam em refugiados em sua própria terra. Ela conclui que esses dispositivos regulatórios sobre o território acabaram fundamentando a desigualdade desses povos perante a lei, negando aos palestinos a aplicação do direito internacional dos povos disporem de si mesmos.

PALAVRAS-CHAVE: geografia, organização de território, política internacional, Oriente-médio árabe, conflito.

\section{LIVING AND WORKING IN OCCUPIED TERRITORY: Palestine and her people}

\section{Ana Maria Maciel Montenegro}

This paper analyzes, from a historical perspective, the different juridical and administrative means as well as the resolutions of international organs in the regulation of a disputed internationaux pour la régu-lation area among Jews and Palestinians - d'une zone de conflit entre Juifs et the Gaza strip. Beginning from Palestiniens - la bande de Gaza. Une reading the press and specialized recherche faite dans la presse et dans academic magazines the author des revues scientifiques spécialisées reveals the difficulties lived by the permet de montrer les difficultés Palestinians in their organization of vécues par les Palestiniens pour life and work, for the restrictions of l'organisation de leur vie quotidienne movement within the Gaza Strip et de leur travail, à cause des blocages territory, that transform them in de la circulation qui les transforment refugees in their own land. She en réfugiés sur leur propre territoire. concludes that those land regulatory La conclusion à laquelle on arrive est devices ended up fundamenting the que ces dispositifs régulateurs sur le inequality of those people before the territoire ont fini par créer l'inégalité law, denying the Palestinians the de ces peuples face à la loi, ne application of the international law permettant pas aux Palestiniens according to which people are the d'avoir recours au droit international owners of their own destinies.

KEYwords: geography, territory organization, international politics, Arab Middle-East, conflict. qui garantit aux peuples de disposer d'eux-mêmes.

MoTS-CLÉs: géographie, organisation du territoire, politique internationale, Moyen Orient arabe, conflit.

Ana Maria Maciel Montenegro - Doutora em Geografia pela Université de Paris VII, desde 1974 e Mestre pela Université de Paris I. Geógrafa pela Pontifícia Universidade Católica do Rio de Janeiro. É docente da Université de Paris XII - CRETEIL - Maître de Conférence. Seus trabalhos tratam sobre turismo e organização de territórios; geografia, sociedade e economia, especialmente em relação ao médio-oriente árabe. 